\title{
COVID-19 PANDEMIC AND THE READINESS OF THE EMPLOYERS IN GEORGIA
}

\author{
SALOME IMNAISHVILI \\ PhD Candidate \\ Georgian Technical University, Georgia \\ Salome.imnaishvili777@gmail.com
}

NINO KAVTARADZE

Doctor of Business Administration, Professor

Georgian Technical University, Georgia

ninokavtaradze0481@yahoo.com

Abstract. The Covid-19 pandemic has posed a major challenge to the entire world. Even for the countries with big economics this challenge turned out to be hard to overcome. The "paused" world tried to fight against the most inexplicable economic crisis with the use of digital technologies. The era of digital technology development is a period of limitless possibilities for modern managers. Managing a company easily and efficiently is already unthinkable without information technology and digital platforms maintaining competitiveness in the market, relieving employees from routine tasks, optimizing processes, taking care of development - these are the minimum requirements, that are difficult to achieve in modern conditions without technological progress. The issue of information security and integration of modern technologies, in the management process, during the COVID-19 pandemic, became even more urgent and vital for some organizations, as many of them had to work remotely for quite a long time during the entire period.

Every good project manager knows that one of the main tools for effectively developing a team and completing a project with the best results is fast and quality communication. To ensure this, companies use platforms where employees can centrally and transparently communicate with each other and monitor the progress of the work process. In the conditions of switching to remote work mode, it has become a daily necessity to hold meetings, trainings, conferences and lectures or lessons online, therefore, it is important to select programs tailored to the specifics of our activity, which are specially designed for this purpose. In this case, Georgia turned out to be quite ready, too. Within just couple of days the country managed to organize the transition of the state as well as private sector to the remote working mode, and got the $2^{\text {nd }}$ place among the top 50 countries, where remote working is the most convenient and comfortable.

KEYWORDS: COVID -19, PANDEMIC, REMOTE WORKING PROCESS, READINESS OF GEORGIA, MODERN TECHNOLOGIES.

For citation: Imnaishvili S., Kavtaradze N. Covid-19 pandemic and the readiness of the employers in Georgia, Globalization and Business, №11, 92-96. https://doi.org/10.35945/gb.2021.11.012

\section{INTRODUCTION}

In December 2019, in the city of Wuhan, China, pneumonia caused by an unidentified pathogen, which massively spread around the world, was declared a pandemic by the World Health Organization on March 11, 2020. In three months, the number of people infected with COVID-19 reached 250,856 , while the number of deaths reached 10,389 people in 164 countries.

Georgia, as a part of the world, had to get involved in the fight against COVID-19, too. Although Georgia was in a much better position than many other European countries in the spring (for example, in Italy 3,000 to 4,000 new cases were revealed daily, while a total of 44 were reported in Georgia), experts believed that the peak of the coronavirus outbreak in Georgia was still too early to come, however, with numerous restrictions already in place, the country still declared a state of emergency for 1 month.

As early as the spring, it was already clear what an impact it would have to the world economy to have a "suspended", struggling with COVID-19 world. Therefore, after doing the civil duty, as the main task, it is necessary for each person, according to his/her responsibility, to contribute to the development of the country, in order to prevent a global collapse. 
This will be the first economic crisis to hit the world since the 2007-2008 global economic crisis, but this time, unlike the previous case, the root cause will be a global pandemic.

Pessimistic economic forecasts multiplied in the last week of February 2020, as this week ended with the biggest drop in the last decade for the world's largest stock markets.

A special report prepared by the American publication Bloomberg on March 6, 2020 began like this: "Coronavirus takes on a global appearance, which could stop the world economy." The publication experts compiled four scenarios of events. The most pessimistic was the last scenario, which involved a pandemic spread of the virus around the world. In the event of a global pandemic, experts estimate the world economy would lose $\$ 2.7$ trillion. In this scenario, global economic growth was equal to $0 \%$.

Against the backdrop of the novel coronavirus, other organizations were talking about the expected difficulties in the global economy, too. On March 2, 2020, a study by the Organization for Economic Co-operation and Development (OECD) was published showing that global economic growth could be halved due to the spread of the novel coronavirus.

In the spring of 2020, it was so inexplicable how COVID-19 would behave and what steps governments and businesses around the world would take with it that it was really difficult to make an accurate forecast, however, analysis by economic experts allowed us to see clearly the scale of the global economic crisis we were about to face.

According to a study published by the "International Monetary Fund" in January 2021, the world economic growth rate for 2020 has improved by 0.9 percentage points compared to the October forecast and is currently estimated at -3.5 percent. To some extent, this figure has also been determined by the approval of COVID-19 vaccines in 2020 and, in part, a colossal increase in governments' debts.

The world's domestic and foreign debt increased significantly, which served to minimize the downturn in the world economy. The number of countries whose public debt exceeded the volume of their GDP exceeded 30. (Papava, 2021) Among them, of course, the state debt of Georgia has increased significantly and in the conditions when the priority sector of the Georgian economy, tourism, has suffered the most around the world, it is difficult to say what levers Georgia will use to rehabilitate the economic situation in the country.

In the conditions of universal self-isolation and quarantine the need for provision of remote services has become even more apparent. According to 2019 data, about 16\% of companies in the world operated completely remotely, although according to the same data, $44 \%$ of companies were not allowed to work remotely at all. It's interesting what the efficiency of the activities of these companies is now?!

\section{BASIC TEXT}

In the second half of March 2020, dozens of companies and state institutions had to arrange to switch to remote working mode within just a few hours. Organizations faced the challenge - how to maintain work mechanism, productivity, safety and employee engagement at the same time, however, employee health safety is paramount and the issue of working remotely was thus addressed. Those who were more or less prepared for this process had some luck.

With modern requirements, nowadays, there are many free and paid programs available to facilitate remote work. Many state institutions and private companies use VPN (Virtual Private Network) technology. It is an encrypted and secure connection that connects the employee's computer to the company's resources. This system allows us to connect two or more devices / networks physically separated from each other into a single network, allowing us to exchange files, share a printer, centralize a network, and work with internal network applications without any cloud storage or other means. It is possible to use different VPN software such as Cisco Anyconnect, FortiClient, Check Point remote access VPN and others. If the company does not have the appropriate VPN infrastructure, it is possible to use Google Remote desktop, AnyDesk, Teamviewer or other similar programs.

In the conditions of switching to remote work mode, it has become a daily necessity to hold meetings, trainings, conferences and lectures or lessons online, therefore, it is important to select programs tailored to the specifics of our activity, which are specially designed for this purpose.

In order to work remotely with comfort, efficiently and safely, according to surveys, employed citizens in Georgia use the following platforms most actively: Zoom cloud meeting, G Suite, Slack, Miro, Trello, Toggl. Through these platforms it is possible to plan meetings, conduct trainings, organize video conferences, manage projects and time, etc. Most importantly, these systems are so flexible that during the work process, it is difficult to find activity that cannot be done remotely: Assigning tasks to employees, making meeting notes, allocating work rooms for specific individuals, sharing and editing documents online, using a virtual board, integrating with various applications, monitoring performance, and more. Most importantly, these platforms can also be used via mobile phone.

Every good project manager knows that one of the main tools for effectively developing a team and completing a project with the best results is fast and quality communication. To ensure this, companies use platforms where employees can centrally and transparently communicate with each other and monitor the progress of the work process. On the one hand, it is easy for the manager to control the work performed and assign new tasks, while on the other hand, employees can intelligently distribute their tasks according to working hours and do not miss deadlines for completing them.

Every program, of course, has its minor disadvantages, which can only be inconvenient for a specific user, in the process of working, but we all agree that not using such programs is simply a crime when time, ease and efficiency are a priority for everyone.

Also noteworthy is the fact that the developers of the above listed programs have made paid versions of their programs available for free for a period of three to six months in order to facilitate business in connection with the pandemic. Which allows, for example, in the case of Microsoft to record 
meetings, and in the case of G Suite to include 250 people in one call, record meetings and go live (with the support of 100,000 viewers).

We should not forget one of the most important challenges of the 21st century either, which is related to the protection and security of personal data. With the advent of modern technology, when almost everything is remotely accessible, the threat of more cyber-attacks has emerged and, consequently, the secure processing of personal data has become the number one task for developers of various platforms. Many applications today have the problem of data protection, especially those that are in high demand and therefore have a large database, however, fortunately, there are quite reliable protection mechanisms that enable data security and applications that have a large number of users have a commitment to do so - protect users' personal information. It is also appreciated that the relevant profile organizations are trying to make information as accessible as possible in this crisis period, which will raise citizens' awareness in terms of cyber hygiene.

Remote workflow is different for the world in usual and pandemic conditions, and all the many studies that have been done to determine the pros and cons of remote work have been based on normal workflows and the normal working rhythm of the world. In fact, there is a big difference between working out of a locked house during a pandemic, along with many other parallel family activities, and generally working remotely, even from the terrace of one of the café-bars.

But still, even during this period one can talk about the advantages and disadvantages of remote work. Advantages: Opportunity of isolation during pandemic; Saving time on not being stuck in traffic jams; Travel and food savings; Socially responsible companies will appear, how they take care of employees, labour safety, comfortable arrangement of workplaces. Disadvantages: Very important for Georgians the problem of socialization; The problem of internet access and technical malfunctions; Security of personal data and processed information in the company; Negative impact on corporate culture; Reducing the sense of mutual responsibility among employees; Bringing family problems to the work.

There are also several important factors to consider: First, it is important to adjust the time to the new reality. One of the disadvantages of working at home is that people work harder and are therefore more productive, but it is important to separate personal life from the work process, which in self-isolation mode is even more difficult. Therefore, if we do not have a specific working time allocated by the company, it is important that we distribute this time ourselves.

Recently, the number of videos of so-called "awkward cases" has significantly increased during live broadcast. Many platforms that support video calling allow users to choose from a variety of backgrounds and virtual accessories, making it easy for them to prepare for online meetings and make them as focused on business as possible when communicating.

We can talk about the readiness of Georgia to meet the process of working remotely during the World Pandemic, based on the answers of the surveyed citizens employed in the state and private structures in the country, based on an independent survey conducted by the authors.

Surveyed employees aged 21 to 60 who are of different professions, are employed in different structures and work in different positions, ranging from specialist to senior managers, to the question of when is their work more effective, while in the office or remotely from work? - 76\% of respondents chose the office. (Figure 1),

Figure 1. When do you think your work is more efficient, when you are in the office or remotely from work? (If your physical presence at work, by profession, is not necessary). Please indicate the reason for the chosen answer in the additional column

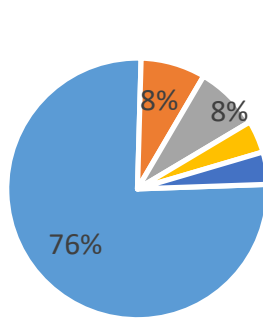
- In office
- Remotely
- Working remotely if not restrictions /discomfort connected to the pandemic
- I think both, based on the fact that while working remotely...
- The only discomfort is working with children

Although $40 \%$ expressed a desire to work on a long-term contract in a company, where they would only work remotely and would have to show up at work only under the necessary circumstances.

Figure 2. Would you work on a long-term contract in a job where you only had to work remotely, with rare exceptions?
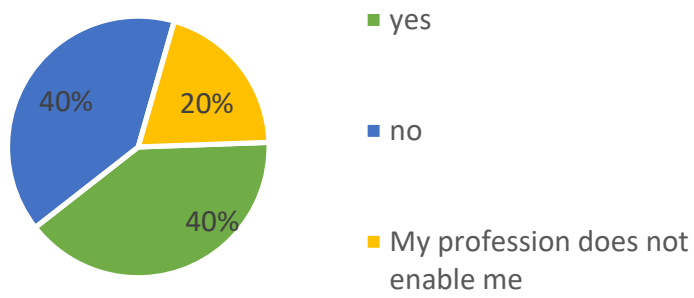

$80 \%$ of respondents use internal networking software. (Figure 3).

Figure 3. How often do you have to use internal networking software during the work process?
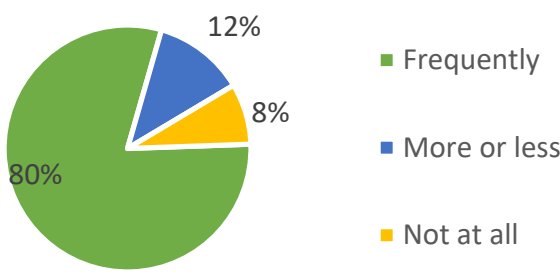

$60 \%$ say that the employer provides them with both material and technical resources (Figure 4) and in almost $80 \%$, in case of technical malfunctions and software defects, the job has an appropriate employee who will provide immediate elimination of the problem (Figure 5). 
Figure 4. How much does the employer provide you with both software and material-technical resources for your remote work?

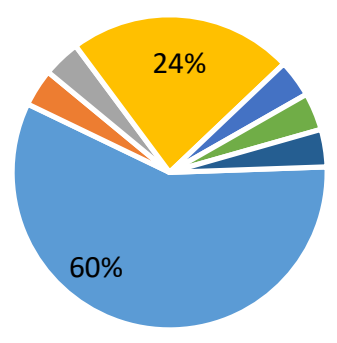

- Work provides material-technical as well as software access

- Work provides access only to the internal software

- Periodically I have to go to work, because...

- Periodically I have to go to work, because...

- I can't work remotely, ...

- My everyday work process ...

- I do not use it

Figure 5. When working from home, in case of a technical malfunction (there is a defect in the software in which you work, there is a defect in the connection, computer, etc.), do you have an appropriate service employee who will be able to eliminate the problem as soon as possible?

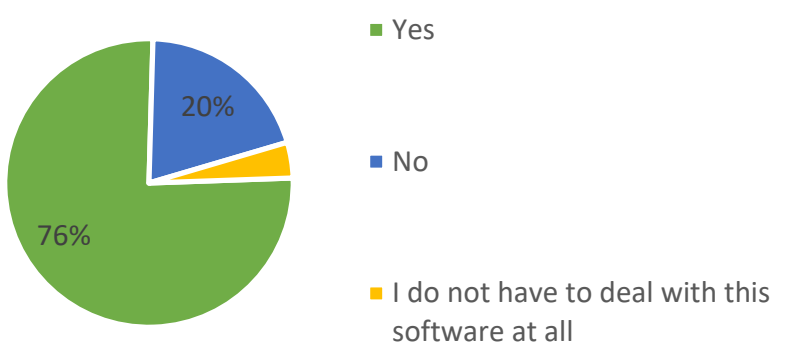

As it turned out, Georgia was quite prepared for the process of transition to remote work, because in just a few days many state or private structures were organized and adapted to modern technologies, so that their efficiency did not deteriorate according to statistics, and in some cases even increased. According to the survey, $48 \%$ of respondents are working on both current and new projects, $36 \%$ on current projects, only $12 \%$ postponed new projects for the period of going out to work (Figure 6).
Figure 6. While working remotely:

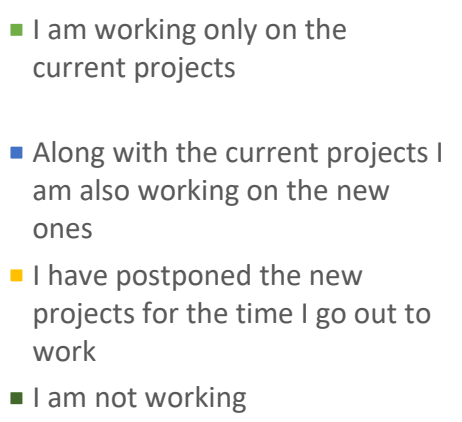

The fact that, according to the survey, almost half of the employed population in Georgia, even in these difficult conditions, which include pandemic-related constraints and discomfort, prefer to work remotely, only indicates that the country has met the challenges quite well and both state structures and private organizations, managed to provide maximum opportunities for employees for an efficient and comfortable work process. Moreover, according to various foreign studies, Georgia is in the leading position in terms of ease of working remotely. Perhaps, after undergone forced practice, many companies will want to introduce only a remote working system in their company.

\section{Conclusion}

It is yet unknown how long the COVID-19 pandemic will last and when the state of emergency caused by it, quarantine and other restrictions will finally end. One year after the coronavirus was discovered, the number of infected people worldwide has reached $110,000,000$, and the death toll has reached $2,400,000$ people in 221 countries. The approval of vaccines and drugs has appeared as the light at the end of the tunnel, and perhaps gradually the countries will return to normal life, but it is clear to everyone that the world will now have to live with COVID-19 and face other still unknown challenges. And as timely and necessary, and less painful for us as a country it was to "harvest the previously sown crop", in the future, every next step towards development, one day, will surely be useful for us, too.

\section{REFERENCES:}

Archvadze, J. (2020). The Impact of The Coronavirus Pandemic on The Forms and Structure of Employment. Globalization and Business, No. 10, 117-120. https://doi.org/10.35945/gb.2020.10.014

Camus, A., \& Gilbert, S. (1948). The plague. London: Hamish Hamilton.

Clark, T.R. (2020). Harvard Business Review - 8 Ways to Manage Your Team While Social Distancing, https://hbr.org/2020/03/8ways-to-manage-your-team-while-social-distancing

Hamilton, M. (2021). Big 7 Travel, Best Places for Remote Working in 2021, https://bigseventravel.com/best-places-remote-working/

IMF (2021). World Economic Outlook Update https://www.imf.org/en/Publications/WEO/Issues/2021/01/26/2021-world-economic-outlook-update

OECD (2020) Interim Economic Assessment, Coronavirus: The World Economy at risk, https://read.oecd-ilibrary.org/economics/oecd-economic-outlook/volume-2019/issue-2_7969896b-en\#page1

Orlik, T., Rush, J., Cousin, M., Hong, J. (2020). Coronavirus Could Cost the Global Economy \$2.7 Trillion. Here’s How, https:// www.bloomberg.com/graphics/2020-coronavirus-pandemic-global-economic-risk

O’Sullivan, F., (2020). Cloudwards - Trello Review, https://www.cloudwards.net/trello-review 
Papava, V., Charava, V. (2021). The problem of the increase of the state debt of Georgia in the conditions of economic crisis caused by the COVID-19 pandemic. https://www.gfsis.org/files/library/opinion-papers/152-expert-opinion-geo.pdf

Simovic, D. (2021). The Ultimate List of Remote Work Statistics - 2021 Edition, https://www.smallbizgenius.net/by-the-numbers/remote-work-statistics/\#gref

Tokmazishvili, M. (2018), Global economic crisis and economic science, globalization and business. No. 5, 17-23 https://doi. org/10.35945/gb.2018.05.002

Worldometer (2021), COVID-19 CORONAVIRUS PANDEMIC https://www.worldometers.info/coronavirus/\#countries

Živković, M. (2019). Slack vs Microsoft Teams: Which Tool Is Ahead of the Game? https://www.chanty.com/blog/slack-vs-microsoft-teams 